\title{
Idiopathic temporal bone encephalocele: Diagnosed and treated during
}

\section{cochlear implantation}

\author{
Alexandros Poutoglidis ${ }^{1}$, Pavlos Pavlidis ${ }^{1}$, Georgios Katsilis ${ }^{1}$, Gregory Alexander Schittek ${ }^{2}$
}

\begin{abstract}
Objective: Meningoencephaloceles of the temporal bone are rare entities. There are two main categories, congenital and acquired. Acquired meningoencephaloceles are more common due to iatrogenic injury to the tegmen tympani which is a common complication during mastoidectomy.

Case Presentation: We present a case of an idiopathic meningoencephalocele that was diagnosed and treated successfully during cochlear implantation via transmastoid approach. Fascia lata graft was used to reconstruct the deficit of tegmen tympani. Audiological outcome has been improved.
\end{abstract}

Conclusions: Idiopathic Meningoencephaloceles present without specific clinical symptomatology and as a result diagnosis delay significant. In literature, there are various surgical approaches with mixed results.

Keywords: Temporal bone, Idiopathic Meningoencephalocele, Sensorineural Hearing Loss

\section{Introduction}

Encephaloceles are classified into cranial and basal. Cranial encephaloceles are the most common and mostly involve the occipital and frontonasal regions. Basal encephaloceles exhibit herniations of the brain or meninges without disconnection of subarachnoid(1,2). Temporal lobe encephaloceles are types of basal encephaloceles and subcategorized into either lateral or midline lesions. Lateral temporal lobe encephaloceles are more common than midline encephaloceles. They may clinically present with clear otorrhea, rhinorrhea, conductive hearing loss, chronic otitis media, middle ear effusion, seizures, meningitis, and intracranial abscess; however, they may also be asymptomatic and incidentally discovered on imaging $(1,3)$. Midline temporal lobe encephaloceles, such as temporosphenoidal encephaloceles, may present as a mass in sphenoid sinus or nasopharynx, with clear rhinorrhea, focal neurologic deficits, or any of the previously mentioned infectious etiologies. Spontaneous meningoencephaloceles are either congenital or idiopathic presenting(1). In idiopathic cases, they are usually located at the tegmen tympani or the tegmen mastoideum. The purpose of the present article is to present a case of meningoencephalocele discovered in temporal bone during cochlear implant surgery. We described our management to restore the deficit effectively.

\section{Case Presentation}

A 24-year-old female, teacher referred to our department with progressive right ear fullness started 12 months ago. She denied vertigo or purulent ear discharge. A history of multiple hearing loss episodes in the past 7 years was recorded. Intravenous treatment with corticosteroids was the treatment of choice because sudden hearing loss was considered the diagnosis. Due to social and professional reasons she was uncomfortable with the hearing aids. On clinical examination, crania nerves function was normal. Nystagmus and fistula test were all absent, and endoscopic ear examination does not exhibit a pulsatile mass or other pathologic signs. There was no visible leak. Pure tone audiogram revealed mild to severe sensorineural hearing loss with right-sided $20 \mathrm{~dB}$ air-bone gap hearing loss. Magnetic Resonance Imaging (MRI) and Computed Tomography (CT) revealed no soft tissue in the middle ear cleft (Figure 1). Based on history and audiometry findings, cochlear implantation was indicated. A postauricular incision was made, and the mastoid cavity was exposed. As the tegmen tympani was revealed, we have found two small meningoencephaloceles, one of them was in contact with the ossicular ossicle (Figure 2). The masses were removed and the defect was closed with a cartilage graft locked in place, and two layers of Solvent-Dehydrated fascia lata were inserted as an underlay technique. 
The whole mastoid cavity was finally filled up and obliterated with soft tissues taken from postauricular skin flap. Cochlear implantation was effectively completed.
There were no postoperative complications. The patient was discharged from the hospital 14 days after the surgery and follow-ups were normal. Finally, the audiological outcome was good.

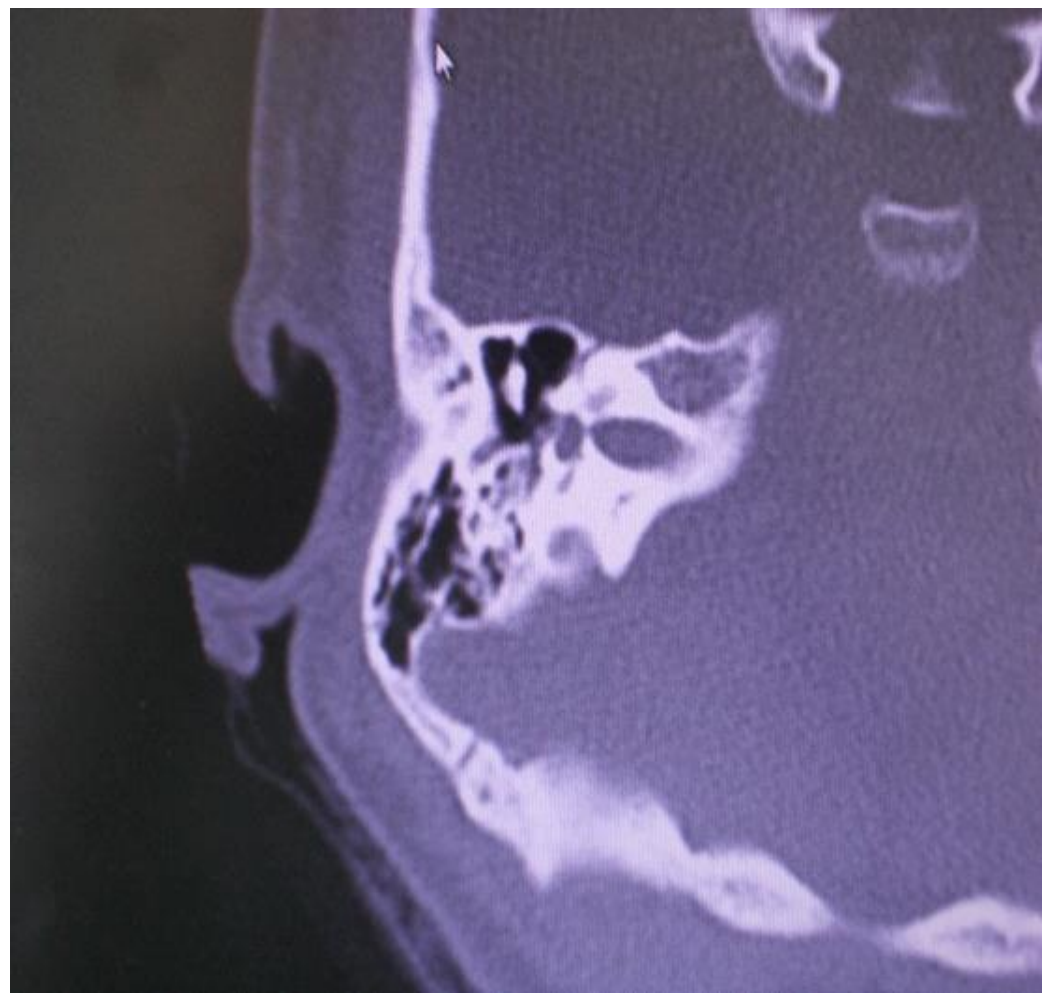

Figure 1: Preoperative CT-Scan shows no pathological findings.

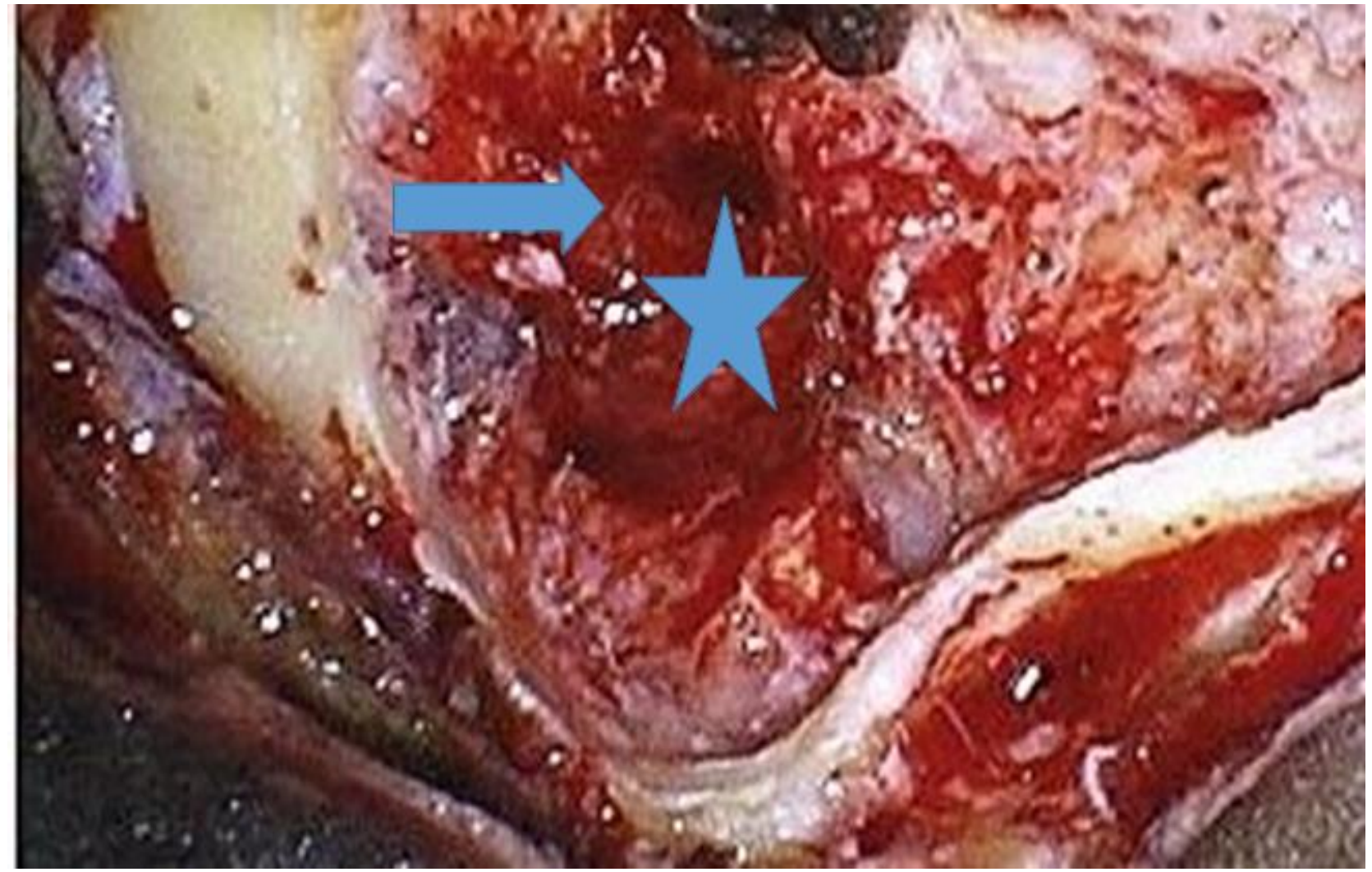

Figure 2: The intraoperative findings of the patient. As it can be seen, we had already contacted a sufficient mastoidectomy. The asterisk and the arrow show where the encephaloceles were found. 


\section{Discussion}

We presented a case of a young woman with the chief complaint of repeated hearing loss episodes. The decision to conduct a cochlear implantation was based both on her personal demands (professional, age, quality of life), and findings of hearing tests.

Encephalocele formation through the temporal bone has multiple etiologies and is broadly categorized as congenital or acquired. Congenital defects are less common than acquired ones and often are developed due to improper ossification of the petrosquamous junction or labyrinthine malformation. The occurrence of temporal meningoceles and/or meningoencephaloceles in the middle ear or mastoid is often insidious in onset and usually only occurs with ipsilateral ear fullness or CSF leak from a tympanic membrane perforation or through the eustachian tube $(4,5)$.

Acquired nontraumatic etiologies of temporal bone encephaloceles include spontaneous perforation, chronic middle ear disease with or without cholesteatoma, and neoplasms. Traumatic etiologies are the most common acquired source and include temporal bone trauma, postradiotherapy dehiscence, and iatrogenic causes(6-8).

Lateral temporal lobe encephalocele (LTE) is a rare entity, and it is a form of basal encephalocele. It has multiple etiologies and is classified into congenital and acquired(911). Due to its nonspecific presentation, imaging is crucial, and both CT and MRI are complementary. MRI is indicative of an interruption of dural line, and images appear as "' tear-drop". MRI is also specific in differentiate brain tissues from cholesteatoma, cholesterol granuloma, or granulation tissues(11-13).

Diagnosis of temporal bone meningoencephaloceles may be challenging. Symptoms may include conductive hearing loss, otorrhea, and recurrent meningitis(10,11). Other less common presenting symptoms are facial nerve weakness, seizures(1,2,6,7) or pulsatile tinnitus(13). It is quite common for these patients to be misdiagnosed and treated as from chronic otitis media $(10,11)$. There are no available guidelines for the management of temporal bone defects; most surgeons rely on their personal experience for the diagnosis and surgical closure of such defects. A variety of surgical techniques have been described in the literature $(14,15)$.

Numerous surgical approaches involving grafting the bony defect have been described and found to be successful for managing meningoencephaloceles.

There have been proposed different surgical approaches. The most common are the transmastoid approach with subtotal petrosectomy and middle-ear obliteration, and the combined middle cranial fossa and transmastoid $\operatorname{approach}(16)$.

By the first approach, a post-aural incision is usually made 3-4 cm behind the retroauricular groove and mastoidectomy is conducted, to exenterate the air cells, remove any diseased mucosa and cholesteatoma if present, and expose the herniated brain tissue widely.
In most cases, the size of the dural deficit is smaller than the bony tegmen deficit(17,18). Fascia can be harvested and placed as underlay after lifting the dura from the surrounding bony edges.

By the transmastoid approach, mastoidectomy is conducted using a standard postaural approach. The meningoencephalic herniation can be identified and resected. By the combined middle cranial fossa and transmastoid approach, the meningoencephalic herniation can be initially managed through a transmastoid route $(19,20)$. The post-aural incision was then extended superiorly as a reverse question mark and a posteriorly based skin flap can be elevated.

\section{Conclusions}

A meningoencephalocele in the temporal bone may cause hearing loss. A CT scan or even MRI in some cases cannot detect very small meningocelles. A surgical exploration in such cases is indicated.

There are several surgical treatment approaches. The ideal one includes exposure and visualization of the encephalocele and its surgical resection. This approach should combine with the repair of the associated osseous or dural deficit.

Author Contributions: AP, PP, GK, GAS: Patient examination and evaluation, Review of the literature, AP: Article writing and revisions

Conflict of interest: All Authors decleare that, no actual or potential conflicts of interest exist in relation to this article.

Ethical issues: All authors declare originality of research.

\section{References}

1. Al-Nashar IS, Carrau RL, Herrera A, Snyderman CH: Endoscopic transnasal transpterygopalatine fossa approach to the lateral recess of the sphenoid sinus. Laryngoscope 2004;114:528-32.

2. Goldwing-Wood DG, Williams HO, Brookes GB. Tegmental dehiscence and brain herniation into the middle ear cleft. J Laryngol Otol. 1991;105:477-80.

3. Ting KN, Liew YT, Prepageran N. Lateral temboral lobe meningoencephalocele: Transmastoid repair with surgical and temporalis graft. Indian J Otol. 2019;25:219-22.

4. Papanikolaou V, Bibas A, Ferekidis E, Angnostopoulou A, Xenelis J. Idiopathic Temporal Bone Encephalocele. Skull Base. 2017;17:311-16.

5. Kutz JW Jr, Husain IA, Isaacson B, Roland PS. Management of spontaneous cerebrospinal fluid otorrhea. Laryngoscope. 2008;118:2195-9.

6. Nahas Z, Tatlipinar A, Limb CJ, Francis HW. Spontaneous meningoencephalocele of the temporal bone: clinical spectrum and presentation. Arch Otolaryngol Head Neck Surg. 2008;134:509-18

7. Jackson CG, Pappas DG Jr, Manolidis S, et al. Brain herniation into the middle ear and mastoid: concepts in diagnosis and surgical management. Am J Otol. 1997;18:198-205.

8. Mosnier I, Fiky LE, Shahidi A, Sterkers O. Brain herniation and chronic otitis media: diagnosis and surgical management. Clin Otolaryngol Allied Sci. 2000;25: 385-91. 
9. Brown NE, Grundfast KM, Jabre A, Megerian CA, O’Malley BW Jr., Rosenberg SI. Diagnosis and management of spontaneous cerebrospinal fluid-middle ear effusion and Otorrhea. Laryngoscope. 2004;114: 800-5.

10. Glasscock Jr MD, Jackson GC, Wiet JR. Surgical management of brain tissue into the middle ear and mastoid. Laryngoscope 1979;89:1743-54

11. Iurato S, Ettore GC, Selvini C. Brain herniation into the middle ear: two idiopathic cases treated by a combined intracranial mastoid approach. Laryngoscope 1989;99:950-4

12. Jeevan DS, Ormond DR, Kim AH et al,. Cerebrospinal fluid leaks and encephaloceles of temporal bone origin: nuances to diagnosis and management. World Neurosurg. 2015;83:560-6.

13. Sanna M, Paolo F, Russo A, Falcioni M. Management of meningoencephalic herniation of the temporal bone: personal experience and literature review. Laryngoscope. 2009;119:1579-85.

14. Sanna M, Fois P, Russo A, Falcioni M. Management of meningoencephalic herniation of the temporal bone: personal experience and literature review. Laryngoscope 2009;119:1579-85.
15. Jackson CG, Pappas DG Jr, Manolidis S et al. Brain herniation into the middle ear and mastoid: concepts in diagnosis and surgical management. Am J Otol. 1997;18:198-205

16. Kantas I, Tzindros G, Papadopoulou A, Marangos N: Midfacial degloving: the best alternative for treatment of transsphenoidal meningocele of the pterygopalatine fossa. Skull Base. 2006;16:11722.

17. Lalwani A K. In: Jackler RK, Brackman DE, editor. Neurotology. St. Louis, MO: Mosby; 2004. Temporal bone encephalocele. pp. 10891095

18. Gubbels SP, Selden NR, Delashaw JB Jr, McMenomey SO: Spontaneous middle fossa encephalocele and cerebrospinal fluid leakage: diagnosis and management. Otol Neurotol. 2007;28:1131-9

19. Kale SU, Pfeiderer AG, Cradwick JC. Bilateral defects of the tegmen tympani associated with brain and dural prolapse in a patient with pulsatile tinnitus. J Laryngol Otol. 2000;114:861-3.

20. Kenning TJ, Willcox TO, Artz GJ, Sciffmacher P, Farrell CJ, Evans JJ: Surgical management of temporal meningoencephaloceles, cerebrospinal fluid leaks, and intracranial hypertension: treatment paradigmand outcomes. Neurosurg Focus. 2012;32:6 